\title{
Analysis of lightning ablation damage performance of glass fiber reinforced polymer materials
}

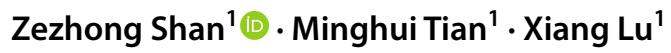

Received: 19 April 2021 / Accepted: 12 November 2021 / Published online: 23 December 2021

(c) The Author(s) 2021

\begin{abstract}
Glass fiber-reinforced polymer materials have been effectively used in civil aviation aircraft, but due to low electrical conductivity, a large area of ablation damage will occur after lightning strikes, which greatly threatens the safety of civil aircrafts. Based on this, the coupled electrical-thermal finite element analysis model for a lightning ablation damage of glass fiber reinforced polymer materials is established, and the analysis results are compared with the experiment, and the error rate is $1.26 \%$, which verifies the accuracy of the model. In addition, different influencing factors are analyzed to study the lightning protection characteristics of glass fiber reinforced polymer on carbon fiber-reinforced polymer laminates. The results show that glass fiber reinforced polymer materials have low lightning resistance, but they can effectively reduce the lightning ablation damage area of carbon fiber reinforced polymer laminates under the joint protection of them and aluminum coating. However, they have different protective effects on different protective forms of laminates. Among them, the thickness of aluminum coating has a higher impact on the lightning protection efficiency of full spraying aluminum protective laminates, and the thickness of glass fiber reinforced polymer materials has a higher impact on the lightning protection efficiency of local spraying aluminum protective laminates.
\end{abstract}

Keywords Glass fiber reinforced polymer · Civil aircraft · Lightning · Carbon fiber reinforced polymer · Ablation damage · Protective effects

\section{Introduction}

Lightning is a common natural phenomenon, which occurs frequently and can release huge energy in a short time [1]. For civil aviation aircrafts, it is inevitable to encounter clouds that are prone to lightning strikes during their operations, making them more susceptible to lightning strikes than other vehicles. Among them, the Boeing 737 was struck by lightning in Colombia in 2010, so that more than 100 people were injured and 1 people was died. The Sukhoi Superjet 100 was struck by lightning in Russia in 2019, so that 41 people were killed. According to statistics, an aircraft will encounter a lightning strike every 1,000-10,000 flight hours.

Technical Editor: Flavio Silvestre.

Zezhong Shan

1210991553@qq.com

1 College of Aeronautical Engineering, Civil Aviation

University of China, No 2898, Jinbei Highway,

Tian Jin 300300, China
In rainy areas, an aircraft suffers an average of one lightning strike every year [2,3]. Lightning strikes have caused many particularly serious flight accidents in civil aviation aircrafts, which pose a great threat to the safety of aircraft operations.

At present, compared with traditional aluminum alloy materials, composite materials have many excellent properties such as higher specific strength, lighter weight, corrosion resistance and so on, which have been widely used in civil aircraft structure. Among them, the use content of composite materials for A350 and B787 has accounted for more than $50 \%$ of all materials [4, 5]. However, composite materials have the characteristics of low electrical conductivity, low specific heat and low thermal conductivity, which is more likely to cause serious safety hazards by lightning stroke $[6,7]$.

The types of composite materials used in aircraft are various, such as carbon fibre-reinforced polymer (CFRP), glass fiber-reinforced polymer (GFRP), natural fiber composites (NFCs) and so on $[8,9]$. There are many studies on the lightning ablation damage of CFRP. For example, Ogasawara et al. [10], Fu et al. [11], and Hirano et al. [12] 
used the coupled electrical-thermal finite element analysis (FEA) models to evaluate the lightning ablation damage characteristics of laminates. Ding et al. [13] and Yin et al. [14] analyzed the effects of different factors on lightning ablation damage of laminates. In addition, many researchers constantly put forward new lightning protection measures to improve the protection ability of CFRP. For example, Sergio et al. [15] optimized the spraying method of protective coating and spraying $0.6 \mu \mathrm{m}$ and $1.2 \mu \mathrm{m}$ copper coatings on CFRP to effectively reduce the lightning ablation damage area of CFRP. Zhao et al. [16], Fallah et al. [17], and Xia et al. [18] also adopted new process protection in CFRP laminates, which improved the lightning protection ability.

However, there are few researches on the lightning ablation damage of GFRP materials, and GFRP materials are mainly used in aircraft radome, wing leading edge, tail leading edge and other structures. They are mainly located in the $1 \mathrm{~A}$ area of the lightning strike zone of civil aircrafts and are more vulnerable to attach the large-energy lightning currents which seriously affect the safety of aircraft operations [8]. At present, Zhao et al. $[19,20]$ have studied the lightning damage of GFRP laminates through experiments, obtained the stress nephogram through the analysis of commercial software CST, speculated the damage range and proved the rationality of the model. However, the analysis process is complex and the accuracy could be further improved and cannot directly analyze and obtain the damage range in the analysis process. In addition, Guo et al. [21] have carried out experimental research on GFRP as protective coating. It is found that GFRP laminates with a thickness of $0.094 \mathrm{~mm}$ as insulating coating can effectively reduce the ablation damage area. Li et al. [22] have studied the impact of humid and hot environment on lightning ablation damage of GFRP laminates. The results showed that the ablation damage area increases by 4.94 times under the peak value of $22 \mathrm{kA}$ lightning current.

Therefore, the lightning damage of GFRP is mainly studied through experiments, and the theoretical analysis process is not perfect. It has been proposed that GFRP as insulating layer can effectively reduce the ablation damage area. However, due to the limitations of experiments, the detailed protection characteristics of GFRP are not fully analyzed. In addition, synthetic fiber is the main type of GFRP, and NFCs have not been studied in detail. Based on these, this paper analyzes the lightning ablation damage of GFRP through FEA model and intuitively generates the lightning ablation damage by using the commercial software ABAQUS, which is compared with the experiment to verify the accuracy of the model. In addition, based on the established model, the protective properties of GFRP materials are analyzed in detail. The analysis results can provide some reference value for the design and maintenance of civil aircraft lightning protection in engineering.
The main works of this paper are as follows: In chapter 1, the importance of civil aircraft lightning protection for civil aircraft and the research status of GFRP lightning damage are introduced; In chapter 2, the establishment process of lightning ablation damage FEA model of GFRP is introduced, and the model is verified by experiment; in chapter 3 , the lightning protection characteristics of GFRP are studied. Aiming at the three research objects of unprotected laminates, full aluminum spraying laminates and local aluminum spraying laminates, the ablation damage characteristics of laminates under GFRP protection are explored from the perspectives of aluminum coating thickness, GFRP thickness and protection area width.

\section{Establishment and verification of lightning ablation model for GFRP laminates}

\subsection{Theoretical model}

The lightning ablation damage of GFRP laminates is mainly caused by Joule heat converted from electric energy, so the FEA model used to simulate the lightning damage of GFRP laminates is suitable. When lightning current propagates in GFRP laminates, the electricity and heat generated will follow the laws of charge conservation and heat conservation.

Assuming that the lightning current is a multi-section steady-state DC current, the electric field distribution of the GFRP laminates is determined according to Maxwell's charge conservation equation.

$\int_{S} J \cdot n \mathrm{dS}=\int_{v} r_{\mathrm{c}} \mathrm{dV}$

where $\boldsymbol{V}$ is the volume of the unit body; $S$ is the surface area of the unit body; $\boldsymbol{n}$ is the external normal direction of $S ; \boldsymbol{J}$ is the current density; $r_{c}$ is the internal volume current.

The current conduction follows Ohm's law [23].

$J=\sigma^{E} \cdot E=-\sigma^{E} \cdot \frac{\partial \varphi}{\partial x}$

where $E$ is the electric field intensity, defined as the negative value of the electric potential gradient $E(x)=-\partial \varphi / \partial x ; \varphi$ is the electric potential; $\sigma^{E}$ is the conductivity matrix.

According to the reference [24], substituting Eq. (2) into Eq. (1), by applying the first chain rule and the divergence theorem to simplify the above equation, the following basic equations for electrical analysis can be obtained.

$\int_{V} \frac{\partial \delta \varphi}{\partial x} \cdot \sigma^{E} \cdot \frac{\partial \varphi}{\partial x} d V=\int_{V} \delta \varphi r_{c} d V+\int_{S} \delta \varphi J d S$ 
The rate of electrical energy dissipated by the current flowing through the material can be expressed by the following Joule's law.

$P_{\mathrm{ec}}=J \cdot E=\frac{\partial \varphi}{\partial x} \cdot \sigma^{E} \cdot \frac{\partial \varphi}{\partial x}$

The amount of electrical energy converted into heat (Joule heat)

$r=\eta_{v} P_{\mathrm{ec}}$

where $\eta_{v}$ is an energy conversion factor (Joule heat coefficient).

When lightning current flows through the conductor, the energy dissipated by the material resistance will increase the temperature of the GFRP laminates, causing it to heat and expand. The basic equation of transient thermal analysis can be derived as follows:

$\int_{v} \rho c_{p} \delta \theta d V+\int_{v} \frac{\partial \delta \theta}{\partial x} k \frac{\partial \theta}{\partial x} d V=\int_{v} \delta \theta r d V+\int_{s} \delta \theta q d S$

where $\rho$ is the material density; $c_{p}$ is the specific heat; $\boldsymbol{k}$ is the thermal conductivity matrix; $\theta$ is temperature; $q$ is the heat flux per unit area flowing into the cell; $r$ is the heat generated in the unit (Joule heat).

Since the temperature of laminates after the lightning strike is extremely larger than the surrounding environment, the heat transfer between the surface of the laminates and the surrounding environment is dominated by heat radiation. The third boundary condition of heat transfer is adopted [25], as shown in Eq. (7).

$q_{r}=F_{B}\left(\theta_{B}-\theta^{z}\right)^{4}-F_{B}\left(\theta-\theta^{z}\right)^{4}$

where $\theta_{B}$ is the ambient temperature; $\theta^{z}$ is the absolute zero value of the temperature scale; $q_{r}$ is the surface heat flux density; $F_{\mathrm{B}}$ is the Boltzmann radiation constant.

Due to the anisotropy of electrical and thermal conductivity of composite materials, the temperature and heat distribution of material are different, forming an anisotropic temperature field. Through heat flux $q=q(\theta)$ and generated heat $r=r(\varphi)$ coupling the above basic equations of electric heating, the potentials, currents, Joule heat and temperature of each unit can be obtained by calculating the two Eqs. (3) and (6). Based on the above calculation method, the commercial software ABAQUS can be used to simulate the damage process of GFRP laminates under lightning strikes.

\subsection{Lightning current waveform}

According to the SAE-ARP5412 manual [26], the lightning current waveform is mainly divided into four waveforms of A, B, C, and D, as shown in Fig. 1.

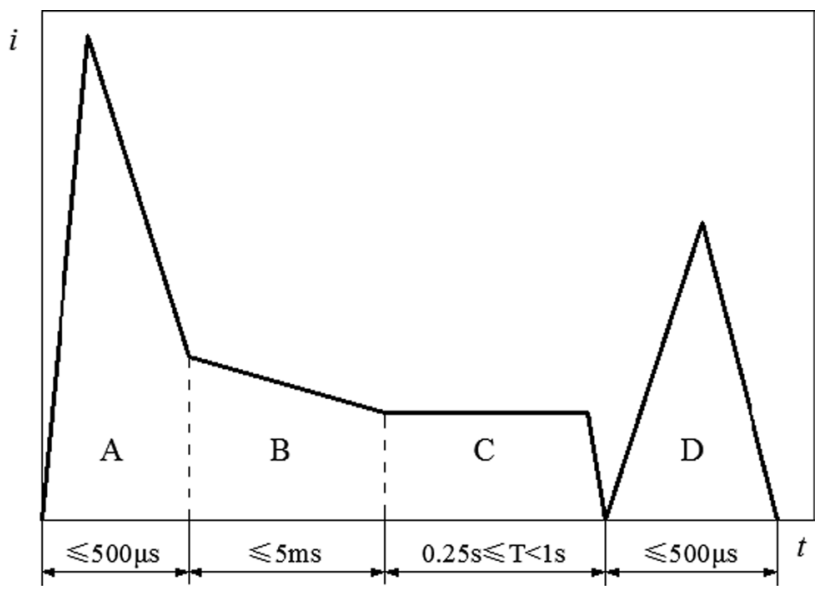

Fig. 1 Typical simulated lightning current waveform [26]

The A waveform is the main waveform of the initial attachment of the lightning current, which transfers the most energy and causes the largest area of lightning ablation damage of the laminates. It can be expressed by a double exponential function, as shown in Eq. (8).

$i(t)=I_{0}\left(e^{-\alpha t}-e^{-\beta t}\right)$

where $i(t)$ is the lightning current; $I_{0}$ is the waveform influencing factor of the double exponential function; $\alpha$ and $\beta$ are the frequency parameters of the double exponential function; $t$ is the time.

\subsection{Experimental study}

This paper refers to the experimental process of reference [19], which used the SSGA200-180 impulse current generator manufactured by the Swiss HAEFELY company, and the applied lightning current parameters were: $I 0=218810 \mathrm{~A}$; $\alpha=11354 \mathrm{~s}^{-1} ; \beta=647265 \mathrm{~s}^{-1}$; action time $\mathrm{t} \leq 500 \mu \mathrm{s}$, the action integral is $2 \times 10^{6}\left(A^{2} \times S\right)$, as shown in Fig. 2 .

The selected material was a GFRP sandwich structures, the upper panel was GFRP laminates, and the middle layer was a paper honeycomb sandwich material. The size was $600 \mathrm{~mm} \times 600 \mathrm{~mm} \times 5 \mathrm{~mm}$, with 40 layers in total. During the experiment, 4 sides were coated with conductive silver glue to ensure full contact with the ground. The damage results are shown in Fig. 3.

It can be seen from the experimental results that the lightning current attached to the GFRP laminates produces a lot of heat and impact force, which leads to the fracture of the GFRP laminates along the four side directions and burns through the whole GFRP laminates. At this time, there are still a large number of lightning currents not released, which are directly attached to the experimental equipment, so that the collapse of the copper ball electrode and the ablation 


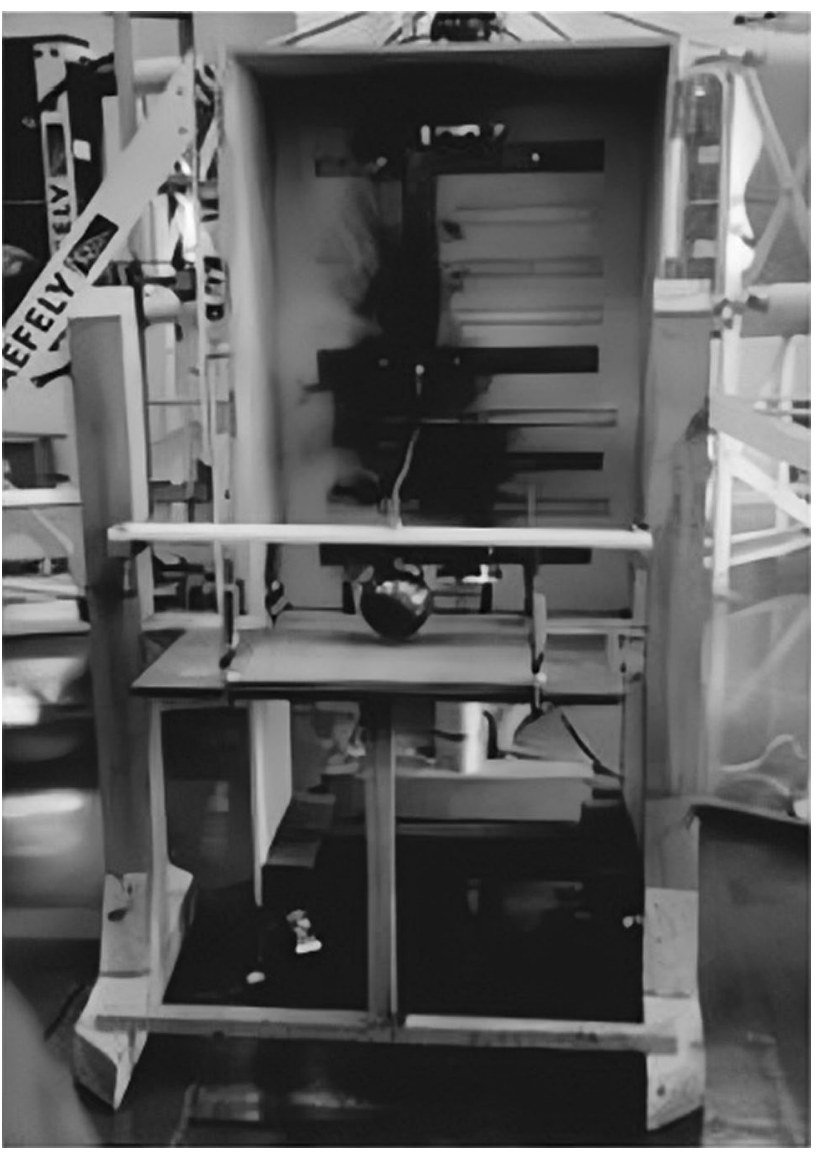

Fig. 2 SSGA200-180 lightning strike experimental platform [19]

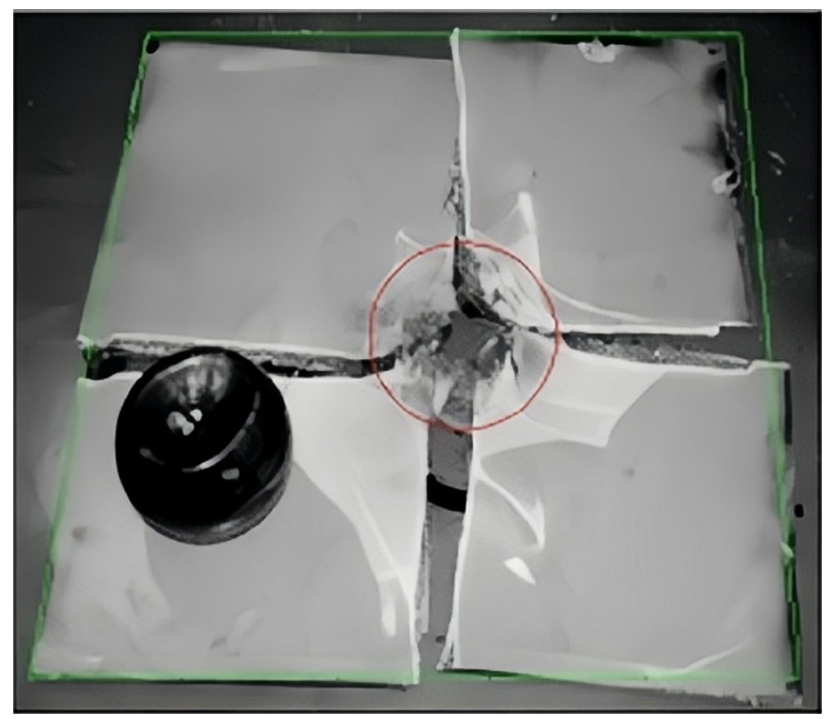

Fig. 3 Experimental results of lightning ablation damage [19]

damage area is not further expanded. The ablation damage area of GFRP laminates is shown in the red area, which is circular in shape and has an area of about $2.216 \mathrm{~cm}^{2}$.

\subsection{Definition of material properties and boundary conditions}

Researchers have shown that the damage of the laminates is consistent with the damage of the top layer, so the damage characteristics of the top layer determine the damage of the entire laminates after being subjected to lightning current $[19,20]$. Therefore, this paper studies the damage characteristics of the upper layer of GFRP laminates and compares them with the experiments to verify the accuracy of the model.

When the temperature reaches $250{ }^{\circ} \mathrm{C}$, the matrix begins to melt and ablation damage occurs; when the temperature reaches $600{ }^{\circ} \mathrm{C}$, the matrix completely melts and the glass fiber begins to melt; when the temperature reaches $1000{ }^{\circ} \mathrm{C}$, the glass fiber boils, the lightning current breaks down the unit, the resistivity is infinitely small, and the lightning current attaches to the next layer. The material properties are shown in Table 1 [27].

According to the experimental operation process, the potential of the side and bottom of the GFRP laminates is set to $0 \mathrm{~V}$, the thermal emissivity between the surrounding and the environment is 0.9 , and the ambient temperature is $25^{\circ} \mathrm{C}$. The meshing attribute is a three-dimensional electric-thermal coupling unit DC3D8E. Moreover, the temperature gradient in the lightning strike attachment area changes greatly. Therefore, the grid elements in this area are encrypted to obtain more accurate results. The final number of grid elements is 46240. The diameter of lightning strike attachment area is about $10 \mathrm{~mm}$ [27]. As shown in Fig. 4, the lightning ablation damage model of GFRP laminates is established.

\subsection{Results analysis and verification}

The FEA model of GFRP laminates is analyzed by commercial software ABAQUS. It can be seen from the analysis process that when the lightning current is applied for $1.35 \times 10^{-11} \mu \mathrm{s}$, the analysis speed suddenly decreases and the area of ablation damage area increases sharply. The ablation damage at this time is shown in Fig. 5. The damage area is $2.244 \mathrm{~cm}^{2}$, and the laminates have been burned through. It is consistent with the experimental results, with an error of $1.26 \%$. The reason for the sharp decrease of analysis speed is that the energy generated by the GFRP laminates in the process of lightning attachment is too large, and the temperature of each grid element of simulated laminates increases sharply,

Table 1 Material properties of GFRP [27]

\begin{tabular}{llll}
\hline $\begin{array}{l}\text { Specific heat } \\
/ \mathrm{J} \cdot \mathrm{kg}^{-1}{ }^{\circ} \mathrm{C}^{-1}\end{array}$ & $\begin{array}{l}\text { Density } \\
/ \mathrm{kg}^{-3} \mathrm{~m}^{-3}\end{array}$ & $\begin{array}{l}\text { Resistivity } \\
/ \Omega \mathrm{m}\end{array}$ & $\begin{array}{l}\text { Thermal conductivity } \\
/ \mathrm{W} \cdot \mathrm{m}^{-2} \mathrm{C}^{-1}\end{array}$ \\
\hline 800 & 2550 & $1 \times 10^{14}$ & 1.2 \\
\hline
\end{tabular}


Fig. 4 Mesh generation, lightning current loading and boundary conditions

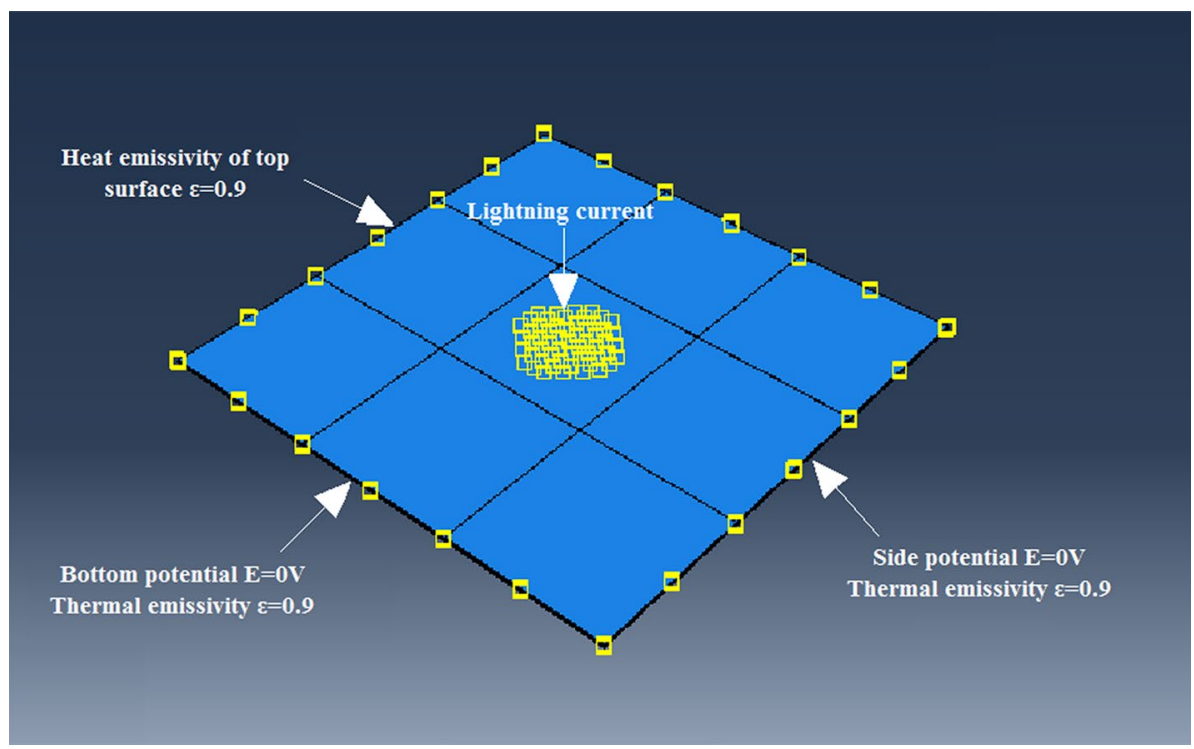

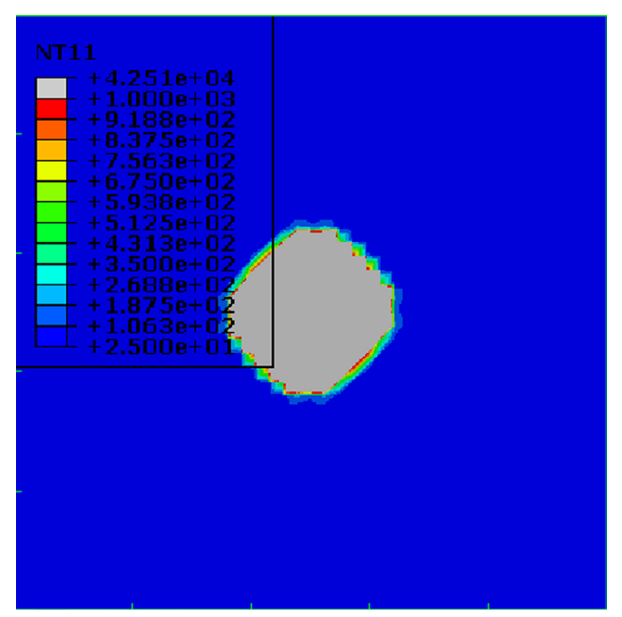

Fig. 5 Analysis results of lightning ablation damage

so that the amount of calculation is too large. It is also in line with the phenomenon that the GFRP laminates breaks along four sides due to excessive energy in a short time and the residual lightning current is transmitted to the experimental platform. Therefore, it can be proved that the FEA model can meet the lightning damage analysis of GFRP laminates.

\section{Effect of GFRP on lightning protection of laminates}

\subsection{Lightning protection analysis of unprotected laminates}

Since GFRP material has lower electrical and thermal conductivity than CFRP material, whether it has a certain
Table 2 Density, specific heat and thermal conductivity of laminates with temperature $[28,29]$

\begin{tabular}{|c|c|c|c|c|c|}
\hline \multirow[t]{2}{*}{ Temperature $/{ }^{\circ} \mathrm{C}$} & \multirow[t]{2}{*}{$\begin{array}{l}\text { specific heat } \\
/ \mathrm{J} \mathrm{kg}^{-1}{ }^{\circ} \mathrm{C}^{-1}\end{array}$} & \multicolumn{3}{|c|}{$\begin{array}{l}\text { Thermal conductivity } \\
/ \mathrm{W} \mathrm{m}{ }^{-1}{ }^{\circ} \mathrm{C}^{-1}\end{array}$} & \multirow[t]{2}{*}{$\begin{array}{l}\text { Density } \\
/ \mathrm{kg} \mathrm{m}^{-3}\end{array}$} \\
\hline & & $k_{x}$ & $k_{y}$ & $k_{z}$ & \\
\hline 25 & 1,065 & 11.8 & 0.609 & 0.609 & 1,520 \\
\hline 330 & 2,050 & 6.02 & 0.31 & 0.31 & 1,520 \\
\hline 360 & 4,250 & 5.46 & 0.28 & 0.28 & 1,520 \\
\hline 500 & 4,200 & 2.8 & 0.14 & 0.14 & 1,170 \\
\hline 525 & 1,800 & 2.33 & 0.12 & 0.12 & 1,170 \\
\hline 815 & 1,850 & 1.4 & 0.072 & 0.072 & 1,170 \\
\hline 3,316 & 2,300 & 1.4 & 0.072 & 0.072 & 1,170 \\
\hline$>3,316$ & 100,000 & 0.02 & 0.02 & 0.02 & 1,170 \\
\hline
\end{tabular}

lightning protection effect as a protective coating for laminates is explored. The size of the GFRP laminates and the CFRP laminates is $150 \mathrm{~mm} \times 100 \mathrm{~mm}$, the thickness of the single layer of the former is $0.01 \mathrm{~mm}$, and the latter is $0.125 \mathrm{~mm}$, a total of 16 layers, and the direction of the layers is $\left[45 /-45 / 0_{2} / 45 / 90 /-45 / 0\right]_{S}$. The properties of the CFRP laminates are shown in Tables 2 and 3 [28, 29]. The applied boundary conditions are consistent with the experimental operation process. The lightning current waveform used is the A waveform, the waveform parameter is $10 / 350$, and the peak value is $31.3 \mathrm{kA}$.

When the analysis reaches $2.91 \times 10^{-10} \mu \mathrm{s}$, the energy generated by lightning stroke is too large, resulting in the reduction of calculation speed. The ablation damage area at this time is shown in Fig. 6a. Figure 6b, c shows the results of ablation damage of the laminates under the protection and unprotection of the aluminum coating after $500 \mu \mathrm{s}$ [30]. It can be seen from Fig. $6 a$ that the shape of the damage 
Table 3 Electrical conductivity of laminates with temperature [28, 29]

\begin{tabular}{llll}
\hline Temperature/ ${ }^{\circ} \mathrm{C}$ & $\begin{array}{l}\text { Fiber orientation } \\
/ \Omega^{-1} \mathrm{~m}^{-1}\end{array}$ & $\begin{array}{l}\text { Vertical } \\
\text { direction } \\
/ \Omega^{-1} \mathrm{~m}^{-1}\end{array}$ & $\begin{array}{l}\text { Thickness } \\
\text { direction } / \\
\Omega^{-1} \mathrm{~m}^{-1}\end{array}$ \\
\hline 127 & $16,812.37$ & 2.97 & 2.97 \\
227 & $17,618.04$ & 3.13 & 3.13 \\
327 & $18,419.6$ & 3.29 & 3.29 \\
427 & $19,230.77$ & 3.44 & 3.44 \\
457 & $19,459.04$ & 18.28 & 18.28 \\
527 & $20,024.03$ & 18.28 & 18.28 \\
627 & $20,828.99$ & 18.28 & 18.28 \\
727 & $21,612.28$ & 18.28 & 18.28 \\
827 & $22,426.55$ & 18.28 & 18.28 \\
3,316 & $7,439.37$ & 18.28 & 18.28 \\
$>3,316$ & 2 & 2 & $1,000,000$ \\
\hline
\end{tabular}

area of the laminates protected by GFRP is approximately circular, mainly because the energy generated by the GFRP material immediately after lightning stroke is large, and the energy is transferred down rapidly, resulting in a large area of ablation damage of the CFRP laminates. Compared with unprotected laminates and aluminum spraying laminates, if the lightning stroke time is the same, the ablation damage area of CFRP laminates under GFRP protection will be the largest. Therefore, GFRP laminates as a separate protective coating not only fail to effectively protect the CFRP laminates from lightning strikes, but also greatly increase the ablation damage area of the CFRP laminates.

\subsection{Lightning protection analysis of full spraying aluminum laminates}

Aluminum spraying protection can effectively reduce the area of lightning ablation damage of laminates. This section discusses the joint effect of aluminum spraying and GFRP material on the protection of laminates and analyzes the influencing factors, which are divided into the following three aspects.

Fig. 6 The lightning ablation damage results of unprotected laminates

\subsubsection{Influence analysis of lightning ablation damage of fully spraying aluminum laminates}

The thickness of the aluminum coating is set to $0.1 \mathrm{~mm}$. The size, number of layers and direction of the CFRP laminates are the same as Sect. 3.1, and $0.01 \mathrm{~mm}$ of GFRP material is laid between them. The peak value of the lightning strike current is $93.7 \mathrm{kA}$, and the waveform parameter is $10 / 350$. The ablation damage results of laminates are shown in Fig. 7. The damage area is $0 \mathrm{~cm}^{2}$, and the temperature is almost the same as the ambient temperature. The damage area is much smaller than the damage results under the protection of aluminum coating shown in Fig. 8, which proves that GFRP material has a certain protective effect on fully spraying aluminum laminates.

\subsubsection{Influence analysis of aluminum coating thickness for fully spraying aluminum laminates}

In order to study the influence of aluminum coating on the ablation damage of laminates, the thickness of aluminum coating is set to increase from $0.02 \mathrm{~mm}$ to $0.15 \mathrm{~mm}$, GFRP material is $0.01 \mathrm{~mm}$, and Section 3.2.1 section lightning current is struck (The same lightning current is applied below). The damage results are shown in Fig. 9. The relationship

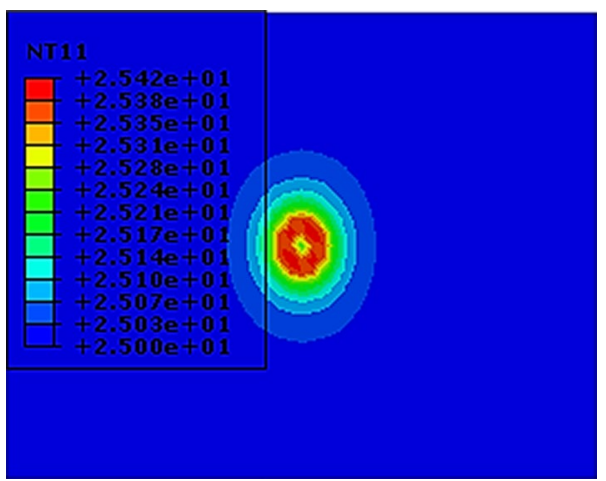

Fig. 7 Ablation damage area of laminates under the joint protection of GFRP and full aluminum spraying

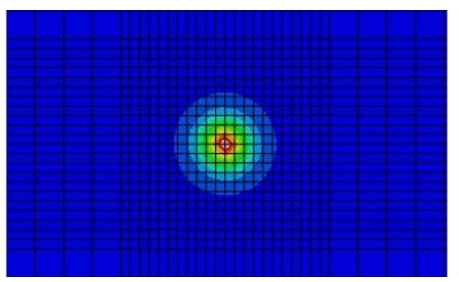

(b) Results of ablation damage (a) Results of ablation damage under the protection of GFRP under the protection of aluminum coating [30]

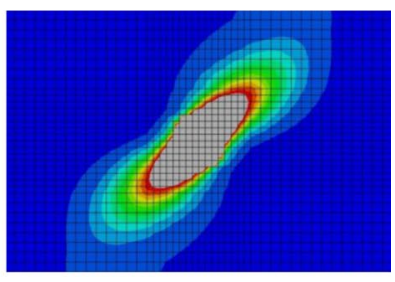

(c) Unprotected ablation damage results [30] 


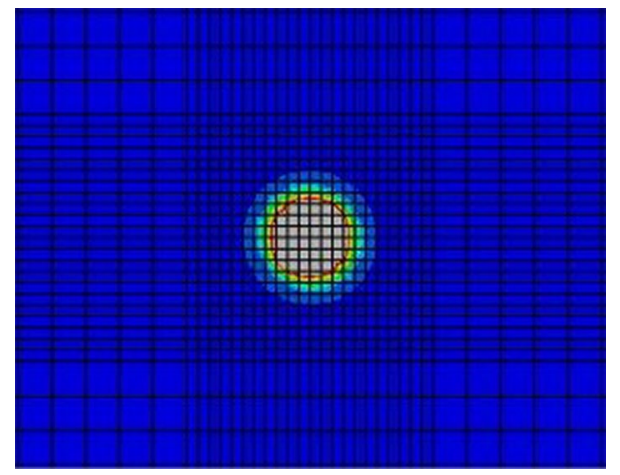

Fig. 8 Ablation damage area of laminates under the protection of full aluminum spraying [30]

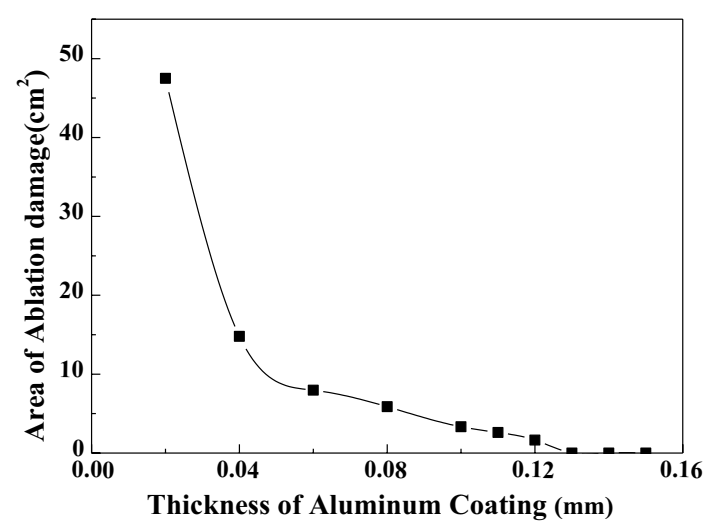

Fig. 9 Effect of aluminum coating thickness on ablation damage of full spraying aluminum laminates

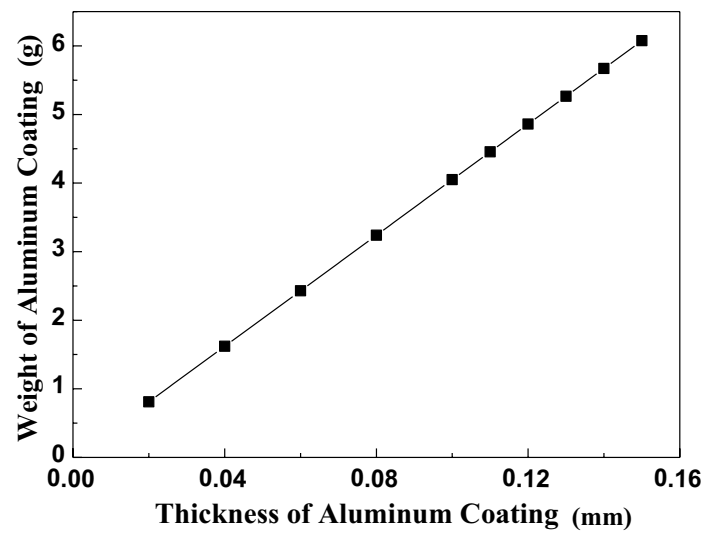

Fig. 10 Relationship curve between thickness and weight of aluminum coating for full spraying aluminum laminates

curve between weight and thickness change is shown in Fig. 10.

It can be seen from Figs. 9 and 10 that under the combined protection of aluminum coating and GFRP material, the ablation damage area of laminates gradually decreases

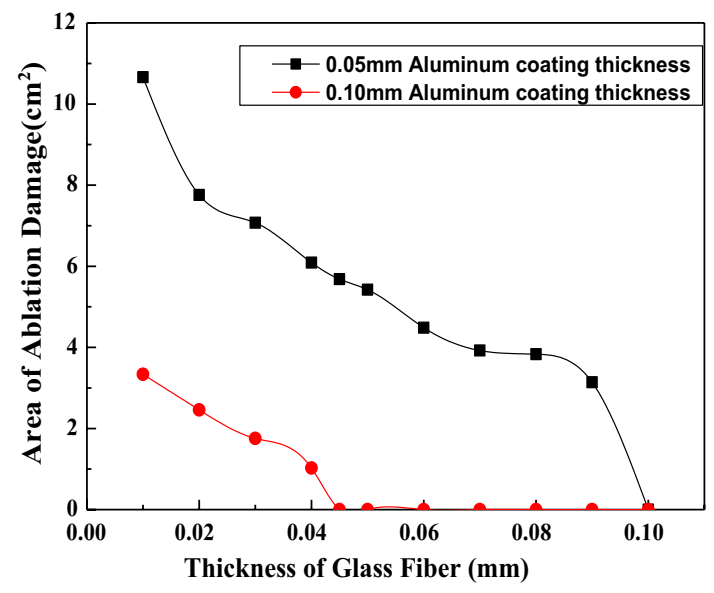

Fig. 11 Effect of GFRP thickness on ablation damage of full spraying aluminum laminates

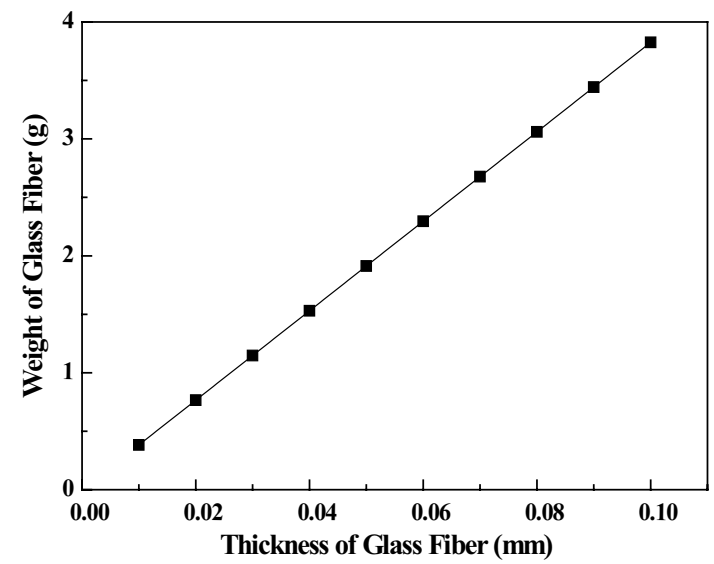

Fig. 12 Relationship curve between thickness and weight of GFRP for full spraying aluminum laminates

and the change slope gradually decreases with the increase in aluminum coating thickness. Among them, the area of ablation damage reduces $47.51 \mathrm{~cm}^{2}$ at the maximum, while the weight of the structure only increases $5.265 \mathrm{~g}$.

\subsubsection{Influence analysis of the thickness of GFRP material for fully spraying aluminum laminates}

In order to study the influence of GFRP material on the ablation damage of laminates, the thickness of GFRP material is set to increase from $0.01 \mathrm{~mm}$ to $0.10 \mathrm{~mm}$, and the thickness of the aluminum coating is set to $0.05 \mathrm{~mm}$ and $0.10 \mathrm{~mm}$. The 
damage results are shown in Fig. 11. The relationship curve between weight and thickness change is shown in Fig. 12.

It can be seen from Figs. 11 and 12 that under the combined protection of aluminum coating and GFRP material, the ablation damage area of laminates gradually decreases and the change slope first decreases and then increases with the increase in aluminum coating thickness. Among them, the area of ablation damage reduces $10.66 \mathrm{~cm}^{2}$ at the maximum, while the weight of the structure only increases $3.443 \mathrm{~g}$.

With the increase in aluminum coating and GFRP thickness, it can effectively reduce lightning damage, but it will increase the structural weight of the aircraft. Under the same increase of unit weight, the influence efficiency of the two factors on reducing lightning damage area is analyzed, as shown in Table 4.

The analysis results show that for the lightning protection of fully spraying aluminum laminates, increasing the thickness of aluminum coating can effectively reduce the lightning damage of laminates compared with increasing the thickness of GFRP material.

\subsection{Lightning protection analysis of local spraying aluminum laminates}

In order to reduce the weight of the structure, some structures on the aircraft often use local spraying aluminum for lightning protection. There are many factors influencing the lightning ablation damage of local spraying aluminum laminates. For this, four aspects are analyzed as followed.

\subsubsection{Analysis of lightning ablation damage of local spraying aluminum and GFRP laminates}

In Fig. 13 is shown a structural dimension drawing of laminates with local spraying aluminum, and the area of aluminum spraying is marked by crosshatched shape. The thickness of the aluminum coating is set to $0.10 \mathrm{~mm}$, the thickness of the GFRP is $0.01 \mathrm{~mm}$, the width $d$ of the aluminum spraying area is set to $10 \mathrm{~mm}$, and the results of the lightning ablation damage are shown in Fig. 14.

From the analysis results, it can be seen that the shape of the ablation damage area of the laminate is similar to the crosshatched shape. The main reason is that the aluminum

Table 4 The effect of aluminum coating thickness and GFRP thickness

\begin{tabular}{llll}
\hline Effect factor & $\begin{array}{l}\text { Structural weight } \\
\text { increment } / \mathrm{g}\end{array}$ & $\begin{array}{l}\text { Damage area } \\
\text { reduction } / \mathrm{cm}^{2}\end{array}$ & $\begin{array}{l}\text { Influence } \\
\text { efficiency }\end{array}$ \\
\hline $\begin{array}{l}\text { Aluminum coating } \\
\text { thickness }\end{array}$ & 5.265 & 47.51 & 9.02 \\
\begin{tabular}{l} 
GFRP thickness \\
\hline
\end{tabular} & 3.443 & 10.66 & 3.10 \\
\hline
\end{tabular}

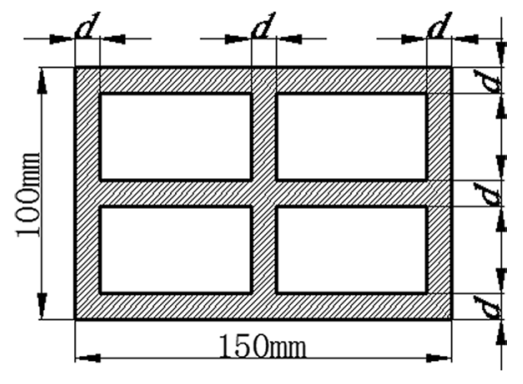

Fig. 13 Dimensional drawing of the structure of the laminates with local aluminum and GFRP spraying

material has strong conductivity and the insulation effect of GFRP, so that the lightning current mainly propagates along the aluminum coating. Only a little lightning current can reach the laminates and generate resistance heat. Therefore, under the main influence of heat conduction factors, the shape of ablation damage area of laminates is approximately crosshatched shaped. In addition, the width of the ablation damage area in the length direction of the laminates is smaller than in the width direction. The main reason is that the width of the laminates is less than the length. When the electric potential is the same, the electric field intensity in the width direction is greater than that in the length direction, which makes the lightning current easier to propagate along the width direction, so that the laminates at width direction generate more energy.

\subsubsection{Influence analysis of aluminum coating thickness}

In order to study the influence of aluminum coating on the ablation damage of local spraying aluminum and GFRP laminates, the thickness of the aluminum coating is set to increase from $0.02 \mathrm{~mm}$ to $0.16 \mathrm{~mm}$, and the thickness of the GFRP is set to $0.01 \mathrm{~mm}$. The damage results are shown in Fig. 15. The relationship curve between weight and thickness change is shown in Fig. 16.

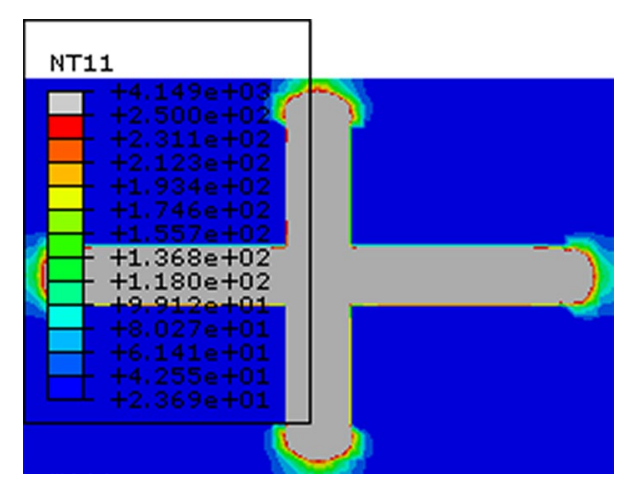

Fig. 14 Ablation damage area of laminates under the joint protection of local aluminum and GFRP spraying 


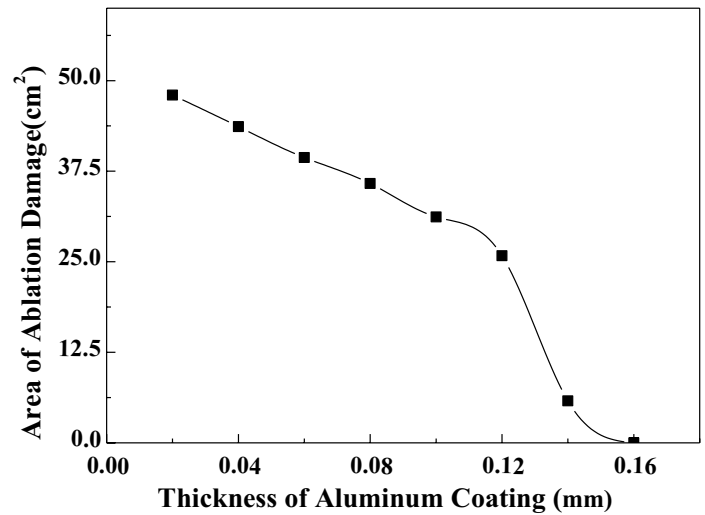

Fig. 15 Effect of aluminum coating thickness on ablation damage of local spraying aluminum laminates

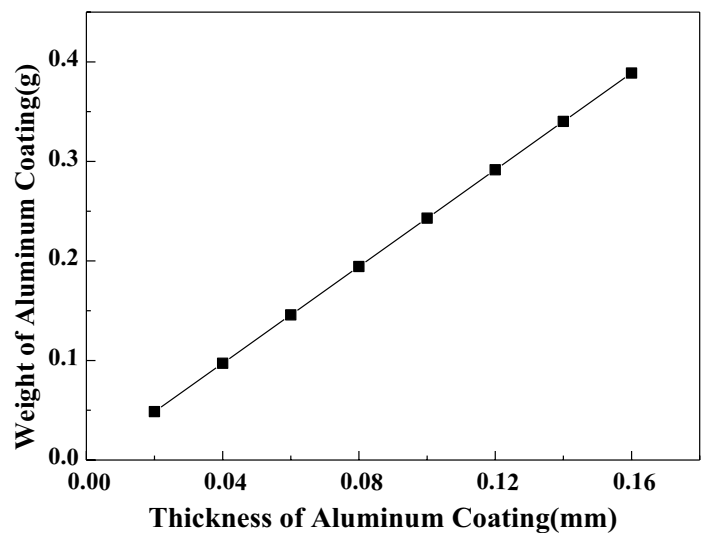

Fig. 16 Relationship curve between thickness and weight of aluminum coating for local spraying aluminum laminates

It can be seen from Figs. 15 and 16 that under the combined protection of local aluminum coating and GFRP material, the ablation damage area of laminates gradually decreases and the change slope firstly remains unchanged and then increases with the increase in local aluminum coating thickness. Among them, the area of ablation damage reduces $48.01 \mathrm{~cm}^{2}$ at the maximum, while the weight of the structure only increases $0.34 \mathrm{~g}$.

\subsubsection{Influence analysis of the thickness of GFRP material}

In order to study the influence of GFRP on the ablation damage of local spraying aluminum laminates, the thickness of the GFRP is set to increase from $0.01 \mathrm{~mm}$ to $0.10 \mathrm{~mm}$, and the thickness of the aluminum coating is set to $0.1 \mathrm{~mm}$. The damage results are shown in Fig. 17. The relationship curve between weight and thickness change is shown in Fig. 18.

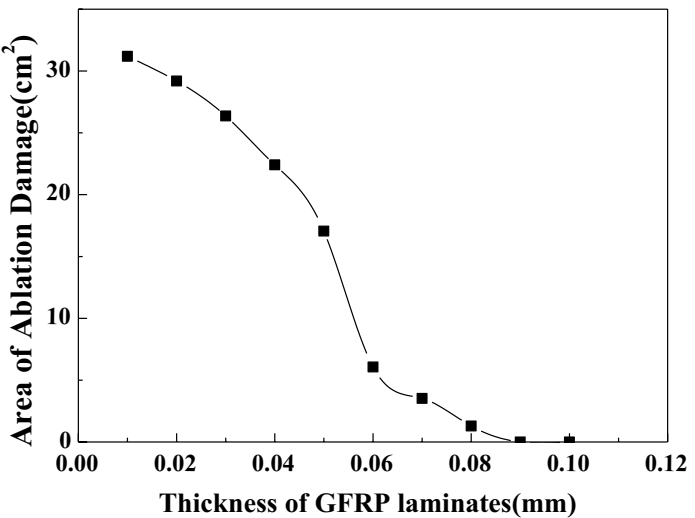

Fig. 17 Effect of GFRP thickness on ablation damage of local spraying aluminum laminates

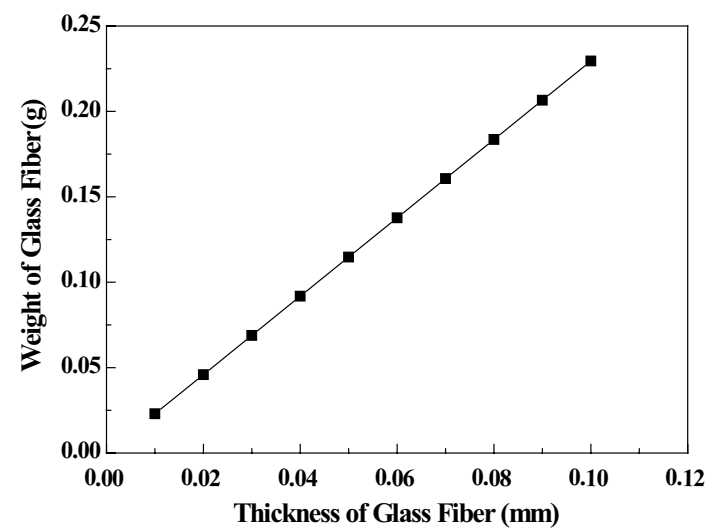

Fig. 18 Relationship curve between thickness and weight of GFRP for local spraying aluminum laminates

It can be seen from Figs. 17 and 18 that under the combined protection of local aluminum coating and GFRP material, the ablation damage area of laminates gradually decreases and the change slope first increases and then decreases with the increases in GFRP thickness. Among them, the area of ablation damage reduces $31.19 \mathrm{~cm}^{2}$ at the maximum, while the weight of the structure only increases $0.184 \mathrm{~g}$.

\subsubsection{Influence analysis of the width of protective area}

In order to study the influence of the width of the aluminum spraying area on the ablation damage of local spraying aluminum laminates, the width of the aluminum spraying is set to from 10 to $30 \mathrm{~mm}$, the thickness of the aluminum coating is set to $0.08 \mathrm{~mm}$, and the thickness of GFRP is set to $0.01 \mathrm{~mm}$. The damage results are shown in Fig. 19. The 


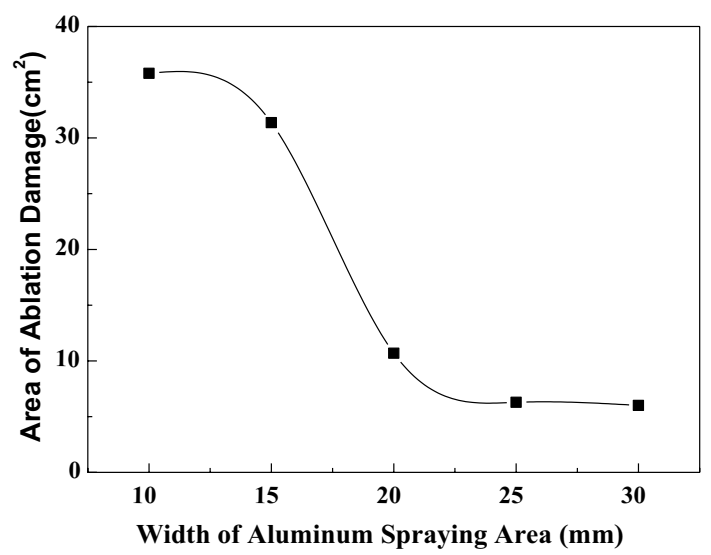

Fig. 19 Effect of the width of the aluminum spraying area on ablation damage of local spraying aluminum laminates

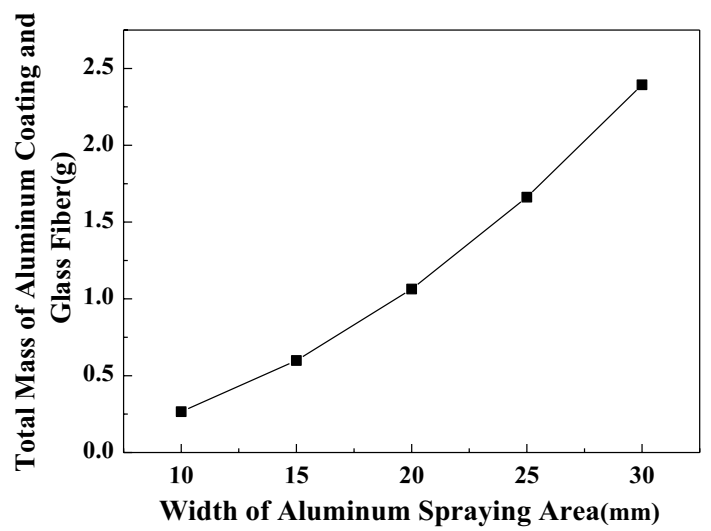

Fig. 20 Relationship curve between width and weight of coating for local spraying aluminum laminates

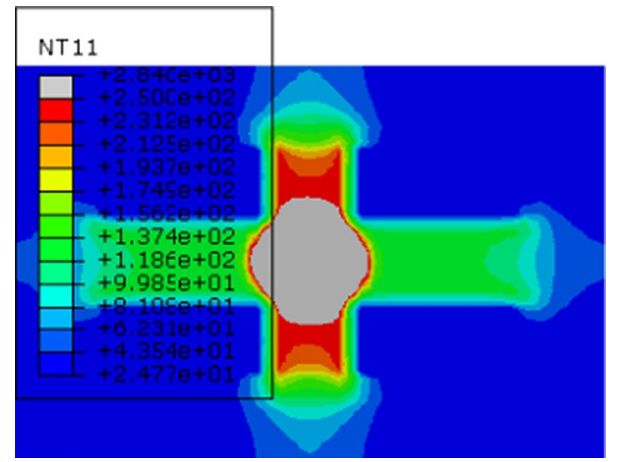

Fig. 21 Lightning ablation damage area of laminates the width $d$ is $20 \mathrm{~mm}$

relationship curve between weight and thickness change is shown in Fig. 20.

It can be seen from Figs. 19 and 20 that under the combined protection of local aluminum coating and GFRP
Table 5 The effect of aluminum coating thickness, GFRP thickness and protection area width

\begin{tabular}{lllr}
\hline Effect factor & $\begin{array}{l}\text { Structural } \\
\text { weight incre- } \\
\text { ment /g }\end{array}$ & $\begin{array}{l}\text { Damage area } \\
\text { reduction / } \\
\mathrm{cm}^{2}\end{array}$ & $\begin{array}{l}\text { Influence } \\
\text { efficiency }\end{array}$ \\
\hline $\begin{array}{l}\text { Aluminum coating } \\
\text { thickness }\end{array}$ & 0.34 & 48.01 & 141.21 \\
$\begin{array}{l}\text { GFRP thickness } \\
\text { Protection area width }\end{array}$ & 0.184 & 31.19 & 169.51 \\
\hline
\end{tabular}

material, the ablation damage area of laminates gradually decreases and the change slope first increases and then decreases with the increases in width of the aluminum spraying area. Among them, the area of ablation damage reduces $29.79 \mathrm{~cm}^{2}$ at the maximum, while the weight of the structure only increases $2.13 \mathrm{~g}$. In addition, as shown in Fig. 21, it is an ablation damage area at $20 \mathrm{~mm}$. Due to the increased width of the aluminum spraying area, the shape of the ablation damage is closer to the full spraying aluminum laminates. Therefore, the reduction amplitude of the damage area is large at this time.

Under the same increase of unit weight, the influence efficiency of the three factors on reducing lightning damage area is analyzed, as shown in Table 5.

The analysis results show that for the lightning protection of local spraying aluminum laminates, increasing the thickness of GFRP can more effectively reduce the lightning damage of laminates compared with increasing the thickness of the aluminum coating and the width of the aluminum spraying area.

\section{Conclusions}

(1) In this paper, the FEA model of lightning ablation damage of GFRP is established and compared with the experimental data. The error between the analytical results and the experimental results is $1.26 \%$, which verifies the accuracy of the model.

(2) The protective characteristics of the GFRP material on the laminates are analyzed. It is found that when the GFRP material is used as a separate protective layer, it will not have a protective effect on the laminates and greatly increase the ablation damage area of the laminates; however, under the joint protection of GFRP material and aluminum coating, it will have better lightning protection effect on laminates.

(3) GFRP thickness, aluminum coating thickness, and protection area width have different influences on lightning protection of laminates with different protection forms. Under the full spraying aluminum protective layer, the aluminum coating thickness has a greater effect on the 
lightning protection of laminates than GFRP thickness; under the local spraying aluminum protective layer, the GFRP thickness has a greater effect on the lightning protection of laminates than aluminum coating thickness and protection area width.

(4) It is worth mentioning that whether NFCs have the potential to replace GFRP materials for the same applications, and the research on their use in lightning ablation damage will become a future research direction.

\begin{abstract}
Acknowledgements The work was supported by the Fundamental Research Funds for the Central Universities, CAUC (Study Code: 3122019080), awarded to Mr. Zezhong Shan.
\end{abstract}

Funding Fundamental Research Funds for Central Universities of the Civil Aviation University of China (CAUC),3122019080,shan zezhong

Open Access This article is licensed under a Creative Commons Attribution 4.0 International License, which permits use, sharing, adaptation, distribution and reproduction in any medium or format, as long as you give appropriate credit to the original author(s) and the source, provide a link to the Creative Commons licence, and indicate if changes were made. The images or other third party material in this article are included in the article's Creative Commons licence, unless indicated otherwise in a credit line to the material. If material is not included in the article's Creative Commons licence and your intended use is not permitted by statutory regulation or exceeds the permitted use, you will need to obtain permission directly from the copyright holder. To view a copy of this licence, visit http://creativecommons.org/licenses/by/4.0/.

\section{References}

1. Wang FS, Ding N, Liu ZQ et al (2014) Ablation damage characteristic and residual strength prediction of carbon fiber/epoxy composite suffered from lightning strike [J]. Compos Struct 117:222-233

2. Liu ZQ, Yue ZF, Wang FS et al (2015) Damage zoning characteristics of composite laminates with different protections subjected to lightning strike [J]. Acta Mater Compos Sin 32(01):284-294

3. Yin JJ, Li SL, Yang Z et al (2018) Test on damage and mechanical property degradation of composite laminate with fastener subjected to lightning strike $[\mathrm{J}]$. Acta Mater Compos Sin 35(05):1131-1138

4. Duongthipthewa A, Lu MY, Du K et al (2021) Experimental and numerical simulation of lightning damage development on composites with/without a carbon-based protection layer [J]. Compos Struct 260:113452

5. Di Z, Xiao Z, Yan H et al (2020) Design of hazard identification system for aircraft power supply system based on SIMPLORER and MATLAB co-simulation[J]. Proceed Inst Mech Eng Part G: J Aerosp Eng 234(11):1770-1787

6. SAE ARP5417 (2008) Aircraft lightning direct effects certification [S]. Society of Automotive Engineers, Warrendale

7. Sun JR, Li YF, Tian XY et al (2020) Experimental and numerical analysis of damage mechanisms for carbon fiber-reinforced polymer composites subjected to lightning strikes [J]. Eng Fail Anal 118:104894

8. SAE ARP5414A (2005) Aircraft lightning zoning [S]. Society of Automotive Engineers, Warrendale
9. Sinha AK, Narang HK, Bhattacharya S (2020) A fuzzy logic approach for modelling and prediction of mechanical properties of hybrid abaca-reinforced polymer composite [J]. J Braz Soc Mech Sci Eng 42(06):1-11

10. Ogasawara T, Hirano Y, Yoshimura A (2010) Coupled thermalelectrical analysis for carbon fiber/epoxy composites exposed to simulated lightning current [J]. Compos A Appl Sci Manuf 41(08):973-981

11. Fu SC, Zhou YH, Shi LH et al (2015) Lightning damage experiment and electric thermal coupling simulation of carbon fiber reinforced composite [J]. J Compos Mater 32(01):250-259

12. Hirano Y, Katsumata S, Iwahori Y et al (2010) Artificial lightning testing on graphite/epoxy composite laminate [J]. Compos A Appl Sci Manuf 41(10):1461-1470

13. Ding N, Zhao B (2014) Analysis of influence factors of lightning ablation damage of composite laminates [J]. J Mater Heat Treat 35(02):186-192

14. Yin JJ, Li SL, Yao XL et al (2017) Analysis on the characteristics of lightning erosion damage of composite laminates with fasteners [J]. J Compos Mater 34(01):104-111

15. Sergio DJ, Gordo E, Morales J (2021) Response of electroless copper coated CFRP laminates to emulated lightning strikes [J]. Compos Part A Appl Sci Manufacturing 140:106184

16. Zhao ZJ, Ma YJ, Yang Z et al (2020) Light weight non-metallic lightning strike protection film for CFRP(Article) $[\mathrm{J}]$. Mater Today Commun 25:101502

17. Fallah P, Rajagopalan S, McDonald A (2020) Development of hybrid metallic coatings on carbon fiber-reinforced polymers (CFRPs) by cold spray deposition of copper-assisted copper electroplating process [J]. Surf Coat Technol 400:126231

18. Xia QS, Zhang ZC, Hao M et al (2020) A double-layered composite for lightning strike protection via conductive and thermal protection [J]. Compos Commun 21:100403

19. Zhao JL, Chen XN, Zhang YS et al (2015) Simulation and test of lightning damage of fiberglass composites [J]. Fiber Reinf Plast/ Compos 01:42-47

20. Ding N, Zhao B, Liu ZQ et al (2013) Lightning ablation damage simulation of composite laminates [J]. Acta Aeronauti Astronaut Sin 34(02):301-308

21. Guo YL, Xu Y, Zhang LA et al (2019) Implementation of fiberglass in carbon fiber composites as an isolation layer that enhances lightning strike protection [J]. Compos Sci Technol 174:117-124

22. Li YC, Xue T, Li RF et al (2018) Influence of a fiberglass layer on the lightning strike damage response of CFRP laminates in the dry and hygrothermal environments [J]. Compos Struct 187:179-189

23. Wang Y (2017) Multiphysics analysis of lightning strike damage in laminated carbon/glass fiber reinforced polymer matrix composite materials: a review of problem formulation and computational modeling [J]. Compos A Appl Sci Manuf 101:543-553

24. Dhanya TM, Yerramalli CS (2018) Lightning strike effect on carbon fiber reinforced composites-effect of copper mesh protection [J]. Mater Today Commun 16:124-134

25. Abdelal G, Murphy A (2014) Nonlinear numerical modelling of lightning strike effect on composite panels with temperature dependent material properties [J]. Compos Struct 109:268-278

26. SAE ARP5412 (1999) Aircraft lightning environment and related test waveforms[S]. Society of Automotive Engineers, Warrendale

27. Wang FS (2016) Lightning damage assessment and protection design of aircraft composite structure [M]. Science Press, China Science Publishing \& Media Ltd

28. Shan ZZ, Luo MJ, Lu X et al (2020) Analysis of lightning ablation damage of composite laminates containing fasteners based on thermoelectric coupling model [J]. J Aeronaut Mater 40(06):71-79 
29. Shan ZZ, Luo MJ, Lu X et al (2021) Analysis of lightning ablation damage of fastener-containing laminates under different factors [J]. J Aeronaut Mater 41(01):83-90

30. Lu X, Zhao M, Shan ZZ et al (2019) Composite lightning protection electric thermal coupling model $[\mathrm{J}]$. J Aeronaut Mater 39(04):49-58
Publisher's Note Springer Nature remains neutral with regard to jurisdictional claims in published maps and institutional affiliations. 